\title{
Two PR-1 Genes from Tomato Are Differentially Regulated and Reveal a Novel Mode of Expression for a Pathogenesis-Related Gene During the Hypersensitive Response and Development
}

\author{
Pablo Tornero, José Gadea, Vicente Conejero, and Pablo Vera \\ Instituto de Biología Molecular y Celular de Plantas (IBMCP), Universidad Politécnica-Consejo Superior de \\ Investigaciones Científicas, Camino de Vera s/n, 46022-Valencia, Spain \\ Received 30 December 1996. Accepted 27 March 1997.
}

Pathogenesis-related (PR) proteins form a heterogeneous family of plant proteins that are likely to be involved in defense and are inducible by pathogen attacks. One group of PRs, represented by the subfamily PR-1, are lowmolecular-weight proteins of unknown biochemical function. Here we describe the cloning and characterization of two closely related genes encoding a basic and an acidic PR-1 protein (PRIb1 and PRIa2) from tomato (Lycopersicon esculentum). We present a comparative study of the mode of transcriptional regulation of these two genes in transgenic tobacco plants using a series of promoter-GUS fusions. Unexpectedly, the chimeric PR1a2/GUS gene is not induced by pathogenic signals but instead shows constitutive expression with a reproducible developmental expression pattern. It is expressed in shoot meristems, trichomes, and cortical cells as well as in vascular and nearby tissues of the mature stem. This constitutive expression pattern may represent preemption of plant defenses against potential pathogens. Conversely, the chimeric PR1b1/GUS gene does not show any constitutive expression in the plant, but it is transcriptionally activated following pathogen attack. Upon infection by tobacco mosaic virus, the PRIb1 gene is strongly activated locally in tissues undergoing the hypersensitive response but not systemically in uninoculated tissues. Furthermore, its expression is induced by both salicylic acid and ethylene precursors, two signals that coexist and apparently mediate the activation of local defenses during the hypersensitive response. We speculate that the different mode of expression of the two genes presented here, together with that reported previously for the induction of other PR-1 genes in systemic, uninoculated tissues, may all be complementary and necessary for the plant to acquire an efficient refractory state to resist pathogen attacks.

Additional keywords: SAR, systemic acquired resistance.

Corresponding author: P. Vera; Phone: 34-6-3877864; Fax: 34-6-3877859; E-mail: vera@ibmcp.upv.es

Nucleotide sequence data have been submitted to GenBank, EMBL, and DDBJ as accession numbers Y08804 (PR1b1) and Y08844 (PR1a2).
Plants have evolved a bewildering array of synergistic mechanisms to defend themselves against pathogenic attacks. Some of these mechanisms are established in the plant before the arrival of the microbe, whereas others are inducible upon the perception of pathogenic signals and can protect the plant not only at the site of infection but also systemically, throughout the plant. All these mechanisms constitute the basis for the natural immunity of plants to many pathogens.

One form of this inducible resistance results in the restriction of pathogen growth to tissues immediately adjacent to the infection site and is mediated by the triggering of local cell death. This localized cell death, manifested in most cases as a visible necrotic lesion, is called a hypersensitive response (HR) (Matthews 1991). The onset of an HR normally precedes the activation of a signaling process throughout the plant that makes it more refractory or resistant to subsequent infections by a broad spectrum of pathogens. This response, called systemic acquired resistance (SAR) (Ross 1961), is common in many incompatible plant-pathogen interactions. During this response, the plant selectively and coordinately activates the expression of a plethora of genes (SAR genes) encoding proteins related to defense (Ward et al. 1991). A subset of these proteins is known as pathogenesis-related (PR) proteins and comprises several gene families, consisting of basic and acidic subfamilies, which appear to locate in the vacuole or extracellularly (Cutt and Klessig 1992). Expression of genes encoding PR proteins has also been found to be induced in dying tissues which are in direct contact with the pathogen and are thus developing HR. Functionally, some PR proteins have been characterized as having antifungal activities in vitro or in vivo, such as chitinases (i.e., PR-3) or $\beta$-1,3-glucanases (i.e., PR-2) (Broglie et al. 1991; Mauch et al. 1988; Zhu et al. 1994), while the biochemical and biological function of other PRs has yet to be identified. The demonstrated antimicrobial activity of some PRs and the fact that they are induced during the HR and SAR responses lead to the suggestion that PRs are at least partially responsible for maintaining the diseaseresistant state (Lawton et al. 1993).

A particularly interesting PR gene subfamily is that encoding PR-1 proteins which have an unknown biochemical function. In tobacco, both basic and acidic PR-1 proteins have been identified on the basis of serological relations and on se- 
quence analyses. Transgenic plants constitutively expressing the acidic PR-1a isoform gene have increased tolerance to the fungal pathogens Phytophthora parasitica and Peronospora tabacina (Alexander et al. 1993), implying that this gene family, or at least some members of it, can play a role in disease resistance. In tobacco, expression of basic and acidic isoforms of PR-1 is differentially regulated. PRB-1, a basic-type PR-1 gene, is activated by the plant hormone ethylene and shows constitutive expression in phloem tissues of the petiole and pedicel abscission zones (Eyal et al. 1993). Conversely, $P R-1$ genes encoding acidic counterparts from tobacco are induced during the HR and at the onset of SAR and are induced by salicylic acid (SA), a possible endogenous signal molecule mediating the SAR response (Ohshima et al. 1990; Van der Rhee et al. 1990; Uknes et al. 1993; Yalpani et al. 1991).

However, in spite of the well-characterized $P R-1$ gene family in tobacco, scant information is available on whether and how this mode of gene regulation is generally established for homologous genes from other plant species. In Arabidopsis, two $P R-1$ genes have been described; one of them is not induced by pathogen attack (Metzler et al. 1991) and the other is generally used as a molecular marker of SAR (Uknes et al. 1992). In tomato plants, at least three cDNA clones encoding different PR-1 isoforms have been described and shown to be induced under different pathogenic situations (Tornero et al. 1993, 1994; Van Kan et al. 1992), but no data exist on the ge- nomic organization and the transcriptional regulation governing the expression of different members of this gene subfamily from tomato. Towards this end, we report here on the isolation of genomic clones of the PRIbl and PRla2 genes from tomato, which encode a basic and an acidic PR-1 isoform, respectively. We introduced different promoter-GUS fusions of these two different $P R-1$ genes into tobacco and performed a comparative study of their mode of expression during development and in response to infection by tobacco mosaic virus (TMV) and chemical inducers of defenses. Interestingly, the newly described PRla2 gene is developmentally regulated and shows no induction over basal constitutive levels upon TMV infection. Conversely, the PRIbl gene is induced by pathogenic signals and shows neither constitutive expression nor developmental regulation.

\section{RESULTS}

\section{Cloning and characterization of genes encoding an acidic and a basic PR-1 protein from tomato.}

The cDNA encoding a previously described basic PR-1 protein in tomato (Tornero et al. 1993) was used as a hybridization probe to screen a genomic library from tomato plants. As a result of this screening, two different lambda clones $(\lambda-17.3$ and $\lambda$-R3) were isolated and characterized by restriction endonuclease site mapping and DNA sequencing. A 2.4-kb DNA

\section{PR 1 b 1}

CATATCAAACTATTTATGCTATATTTAATACTTATTTAAATCGTAACTATTTATTTCTAA -881 ATTGCAGCTCTAACACTTTTTAAAAAGTTTTTTAAAATTTTCTTTCGAAGCTACAAGGATT -821 GAGGCAGTTTCTAATTTCCACATAaaggaCCa.aaAATTGTTTTGGTTTAAGTGTGTCTA -761 TCACTCCATTGTTTGTTGTTTTCATTATATCCATTATATCCAAATTGCTTTCAATGACT -701 AACAAATACTTGAGTCTTCTCTCTCTCATAGAATAACTTTCTTCCATAAATCCACGTAAO -641 GCGGCECAATAAGTGTTGTTTAATATTATCTAAATAATAGAGTAAAGTATGATTATTCTT -581 TAAAGCATATAGTATTTCCTTAATCACACGACATGCAATCTCCTPTGAATTTTCTTCACA -521 TGTGAATAAAATTCCACAAAGTTTPAATTTAACAATTTTCACAAATTTGATTAAATTGAA -461 CAATCAAAGTTTGATAAATATCTPATCGAAACCAAAAGTGTTCACTTTTGAAAAATATAa -401 aggaccaaaaAAGATCACITT"TGACAATCTTaaggaccaaaaTTGCTCTTATCATACATA -341

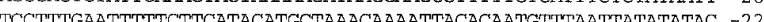
CAAAATACACAAGAGACTATTTTGAACTTACTATCAAAGATAAGAGACCATTTTTATCAT -10 TTCCTCTACTAATARTTTCCTTTGAATTTTCTTCACACATACTTAGCAAAATTCCACAAT -4 TTTTACTLALaAaTACACTACTIATCTCACGTTTATAATCACAATAACTTAGATTTATTT 20 TCTCTGCACTAAACCTAAAGAAAAATGGGGTTGTTCAACATCTCATTGTTACTCACTTGT 80 \begin{tabular}{ccccccccccccc}
$M$ & $G$ & L & F & N & I & $S$ & L & L & L & T & C & 12 \\
\hline
\end{tabular} GCGGTTCATAACGATGCCCGTGCCCAAGTCGGAGTCGGGCCTATGTCTIGGGATGCCAAC 200

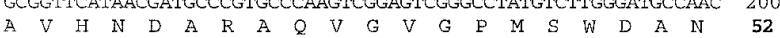

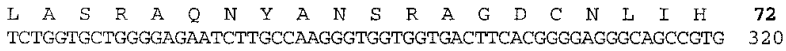
$\begin{array}{llllllllllllllllllllll}S & G & A & G & E & N & \text { L } & \text { A } & \text { K } & G & \text { G } & G & \text { D } & \text { F } & \text { T } & G & \text { R } & \text { A } & \text { A } & V & 92\end{array}$

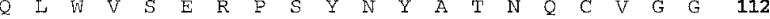
AAAAAGTGIAGACATTATACTCAAGTAGTCIGGCGCAACTCAGICCGACIAGGTTGTGI 140 $\begin{array}{llllllllllllllllllllll}K & K & C & R & H & Y & T & Q & V & V & W & R & N & S & V & R & L & G & C & G & 132\end{array}$ CGGGCACGTTGCAACAACGGATGGTGGTTCATTTCTTGCAACTATGATCCTGTAGGCAAC 500 $\begin{array}{lllllllllllllllllllll}R & A & R & C & N & N & G & W & W & F & I & S & C & N & Y & D & F & V & G & N & 152\end{array}$ TGGATCGGACAACGTCCTTACTAAAATGATGTATACTTATGACATGTTGCTAGTATTAAA 560

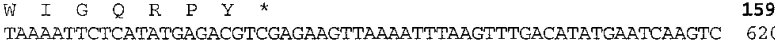
AAACTCCTATCTAAAATATTAAGGGATTAAATATTGAACATCTATAATTATTATTATTTC 680 CCTTTGATGT'TGCTAATATGAATAATTCCACATACCATATGTCATAATGGGC'TAAGT 740 TTAAGCATGGCATATATTAATTAGGCACATCAAGCACTTATCTAAACACGTAACTATTTA 860 TTCATAAATTCA

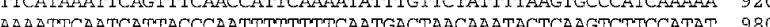
AAAATTCAATCATY TACCCAATTTTTTTTCAATGACTAACAAATACTCAAGTCTTCCATAT 980 TCTCTCATACAATAATGGCCTAAAACTATATTTTCATAAAATATTTTATAGGTGAAAATT 104 GAATTWTATCCTTTCTTGACCTATTGTCTTAGATTTGAATACCAGAAATAAAAACAAATA 1100 ATATCICGTCAGGAAAAAAAAATTGTACCCCTAACAAACGTTTAAATTTAATAATTTTCA 1220 AGGGAGTCTATTGAAACTACTAAAAAGATAAGGAAGCCTTTTTGTCATTTCTCTATAATT -281

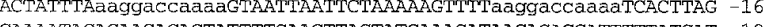

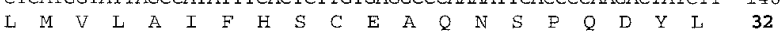
TTGGCATCCCGAGCACAAAACTATGCCAACTCAAGAGCTGGTGATTGTAACTTGATTCAT 260 CAATTGTGGGTGTCCGAGAGGCCAAGCTATAACTACGCTACCAACCAATGTGTTGGTGGA 380 TGATTATTAAGTACTGCATCTTCTTGTTTCCATAAAACATTAATATACATAAAATTTTAA 800 TTGCTATTTATTGAAAAAATTTACGTAGCATGAAATTAAATAAATTGGCACATATTTAAA 1160

\section{PR 1 a 2}

AGTIGGACATAGATTCTTTATTTCTTIAGAATTATAAAATATACGTATTCAAAATTTAAG -900 TGGTCGTAAATTAATACAAAAGTCAAGAAAACTCTTCATTCARAATGGAATATGAATTCA -840 CGCATCAGTCITTTGAACACTTTAACACTTTAATITGAAAAATTATGTACAATATATCCGTT -780

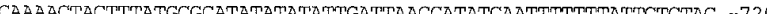
CAAARAGCI

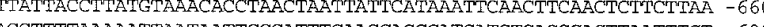
ACGTTTMAAAAATHATAATTCCCATTIGAAGCAGCCATGAIGTGAGGCAGTTAATTCT -600 ACACAAAGAACCACATATTAAGTGTCCACACTTTGTTTATTATGTTTTCATTATATCCAA -540 ATTGCTTAATTTCAATGACTAACAAAAGAATAATTTTCTTTTCATACATTCAAggCgoCt -480 CAATAATATTGATGACCCAAAATCAATTTGTCATAAAATATTTTATAGGTAAAAACTGAA -420 TTGCATCCTTTTTCTATTAGAGGTTTTGAATACAAACCCGAAACATAGATAAATATTAT -360 TTAGATTGAATTTTCCTTTAAAAAAGCTTACGGTGATGCAAATTAAATTAATTAAGACTC -300 CAAAACACATTTCGAATATCTAAAATTAAAGTATGACAATTATTTPAAAGTATATATAGTA -210

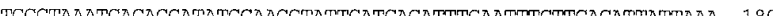
ThT -120 TGAAAAAACTTABAaaggaccaåaGTAATPAATTCTAAAAAGTTTaaggaccaaaaTTG -60 CTTAGCAAAATTCCACAATTTTTACTLULZaATACACTACTTATCTCACATTTATAATCA 1 CAACAACTTAAATT"TATTTTCTCTCAAAGCAAAAATGGGGTTGTTTAACATGTCATTGTT 61 $\begin{array}{rrrrrrrrrc}M & G & L & F & N & M & S & \text { I } & \text { L } & 9 \\ \text { ACTMATGACTTGTCTCATGGIATPAGCCATAITTCACTCTTGTGATGCTCAAAATTCACC } & 121\end{array}$ $\begin{array}{lllllllllllllllllllll} & M & T & C & L & M & V & L & A & I & F & H & S & C & D & A & O & N & S & P & 29\end{array}$ CCAAGACTATCDCACGTTCACARCGACGCCCGTCCCCAMCTCOGACTCGCCCCAMTCDC 181 O D Y I E V H A F A V G V G D M S 181 TTGGGATGCCGACTTGGAATCCCGAGCACAAAGCTATGCCAACTCAAGAGCGGGTGATTG 241 $\begin{array}{lllllllllllllllllllllll} & \text { W } & D & A & D & L & E & S & R & A & Q & S & Y & A & N & S & R & A & G & D & C & 69\end{array}$ TAACTTGATTCATTCTGGTTCAGGGGAGAATCTTGCCAAGGGTGGTGGTGACTTCACGGG 301

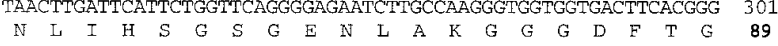
GAGGGCCGCTGTGGAATTTGGGTGTCGGAAAAGCCAAACTACAACTACGATACGAATGA 361 $\begin{array}{llllllllllllllllllllll}R & A & A & V & E & L & W & V & S & \Xi & K & P & N & Y & N & Y & D & T & N & E & 109\end{array}$ ATGTGTTAGCGGAAAATGTGCGGACATTATACTCAAGTAGTCTGGCGTGACTCAGTTCG 421 $\begin{array}{lllllllllllllllllllllll}C & V & S & G & K & M & C & G & H & Y & T & Q & V & V & W & R & D & S & V & R & 129\end{array}$ ACTAGGTTGTGGTCGGGCTCTTTGCAACGACGGGTGGTTTATTTCTTGCAACTATGATCC 181

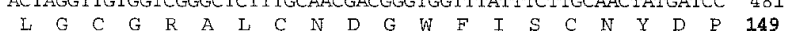
TGTAGGCAATTGGGTCGGACAACGTCTTACTAAAATGTTPTTTWTTTTGTATGATGTGTA 541 $\begin{array}{lllllllllllllllllllll}V & G & N & W & V & G & Q & R & L & T & K & M & F & F & F & L & Y & D & V & * & 168\end{array}$ AGGGATCAAATAATTATTATTATTTCCTITGATCTTTGCTAGTATGAATAATTCCACATA 601 CCATATGTTCATGGTATAGTGGGCTTAAGTTGATAATAAATAAAGTTTTTCTATTTTATTT 661 AAATA.AGATTAAAATACATGGCATAATGGTAAAATAATTATTATTGTCTTATGCAAATTA 721 CGAGAGTTAAATTATTAAIT'TTTPTAAGTGTAAAGACGATCATAGATTCTTTATATCTTA 781 TAAAATGAATTATATATTTAAAAACGGTTTGAAATGATATATAAGTAGAGGCGGATCYAG 841 GATTTGAAGGTAATGGGTGTCATATCGTTAAGTCTCAATCGTTTTGTGATTTTTTCATCACA 901

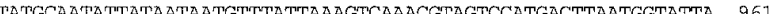
TATGAATATIATAATAATGTTIATTAAAGTCAAACGTAGTCCATGACTTAATGGTATTA 961 ACACTICA 1021 MAACARATGAAM 1081 CTTGTGTCCAGGGGTGACAGATTAGTTTTTCATAAGTTTTATATGCATAAATATATACAT 1141

Fig. 1. Nucleotide and deduced amino acid sequences of the PRIb1 and PRIa2 genes. The deduced amino acid sequence is given below the nucleotide sequence. The transcriptional start sites are indicated in bold. Putative TATA boxes are in underlined lowercase. The GGCGGCTC motifs are in underlined lowercase italics. The conserved and repeated sequences motifs (AAGGACCAAAA) in the promoter regions of these two genes are in lowercase. 
fragment from $\lambda-17.3$, identified by hybridization with the cDNA, carried the complete coding region. Part of the assembled nucleotide sequence of this DNA fragment is shown in Figure 1. This DNA segment contains a single open reading frame (ORF) preceded by 985 bp of 5'-flanking DNA and followed by 1,400 bp of 3'-flanking DNA. A computer-based DNA comparison indicates that this $P R-1$ gene encodes the bona fide pathogen-induced mRNA represented by the cDNA clone pTE28.1, which encoded the basic PR1b1 isoform (Tornero et al. 1993). The transcriptional start site of the PRIbl gene was determined by primer extension using a $5^{\prime}$-endlabeled primer complementary to nucleotides +76 to +97 and mRNAs from tomato plants treated with ethephon (data not shown). Through this analysis, the predominant $5^{\prime}$ terminus (position +1 ) was localized to the A residue 44 nucleotides upstream of the initiator ATG codon (Fig. 1). A putative TATA box is found at position -33 , and a CAAT-like sequence resides at -44 . At the $3^{\prime}$ end of the gene, different consensus sequences for polyadenylation are found.

Similarly, a 3-kb DNA fragment from $\lambda$-R3 carried the complete coding region for a novel PR-1 protein member, which was designated PR1a2 because of the acidic pI of the deduced polypeptide (see below). Part of the assembled nucleotide sequence of this DNA fragment is shown in Figure 1. The DNA segment contains a single ORF encoding the PR1a2 polypeptide. The ORF is preceded by $1,600 \mathrm{bp}$ of $5^{\prime}$-flanking DNA and is followed by 1,400 bp of 3'-flanking DNA. By analogy to the PRIbl gene described above, the transcriptional start site of the PRla2 gene was assigned to the A residue $35 \mathrm{nu}-$ cleotides upstream of the initiator ATG codon (Fig. 1). A putative TATA box is similarly found at position -33, and a CAATlike sequence resides at -44 . At the $3^{\prime}$ end of the gene, two different consensus sequences for polyadenylation are found.

The encoded PR1a2 polypeptide has 168 amino acid residues and contains an N-terminal signal peptide of 25 amino acids that after cleavage would result in a mature protein of 143 amino acids with an estimated molecular weight of 15,886 and an acidic pI of 4.92. Comparison of the derived amino acid sequence of this new acidic PR1a2 with PR1b1 and with different PR-1 proteins previously identified in tomato and other plant species revealed high identity in the coding regions (data not shown). Interestingly, the newly identified PR1a2 was more homologous to the basic PR1b1 (87\% identical amino acid residues) than to the previously identified acidic PR1a1 isoform (51\% identical) from tomato (Tornero et al. 1994). The amino acid sequences of the deduced PR1b1 and PR1a2 proteins are compared in Figure 2A. Most of the amino acid changes observed correspond to single nucleotide substitutions in the coding regions, indicating that the homology between these two proteins is even higher at the nucleotide level (92\% identical). PR1a2 contains a carboxy-terminal extension, relative to the basic PR1b1, which presumably could dictate the final localization of the protein, as has been suggested for other PR proteins (Neuhaus et al. 1991).

Computer-aided nucleotide comparison indicated that the high identity existing in the ORF regions can be extended to the proximal $5^{\prime}$ promoter regions of the PRIbl and PRla2 genes (50\% identity over a stretch of 850 nucleotides). Sequences were identified which are highly conserved if not identical in these two promoters. This homology is highest in the promoter regions close to the initiator ATGs and extends along a stretch of 150 nucleotides upstream of the ATG initiation codons (Fig. 2B). A conserved region of 44 nucleotides containing a direct repeat of the 11-nucleotide sequence AAGGACCAAAA is separated by 21 and 22 nucleotides in the PRIb1 and PRla2 promoters, respectively (Fig. 2A). This 11bp sequence is found three more times along the promoter region of the PRIbl gene (Fig. 1), at positions $-368,-400$, and -795 , with similar spacing between the first two of these (Fig. 1). Additionally, the 8-bp conserved sequence motif GCCGCCTC is found at positions -641 to -634 of PRIbl and at positions -487 to -480 of PRla2 (Fig. 1). Interestingly, promoters of ethylene-inducible $P R$ genes from diverse dicotyledonous species contain this 8-bp consensus sequence. In Nicotiana, this core sequence is present as a direct or inverted repeat and is necessary for induction of the corresponding $P R$ genes by pathogenic attack or by ethylene (Meller et al. 1993; Alonso et al. 1995; Eyal et al. 1993 and references therein). Besides this element, no other conserved motifs were found in any of the two promoters under consideration.

The lack of more significant homology in the promoters of these genes, encoding for closely related proteins, is in agreement with their completely different mode of transcriptional regulation (see below).

\section{Developmental and tissue-specific regulation of the PRIa2 and PRIb1 gene promoters.}

Chimeric PRIb1/GUS and PRla2/GUS reporter constructs were introduced into tobacco and used to study gene expression. The chimeric PR1b1/GUS gene was constructed by fusion of the region from nucleotide -914 to nucleotide +56 of

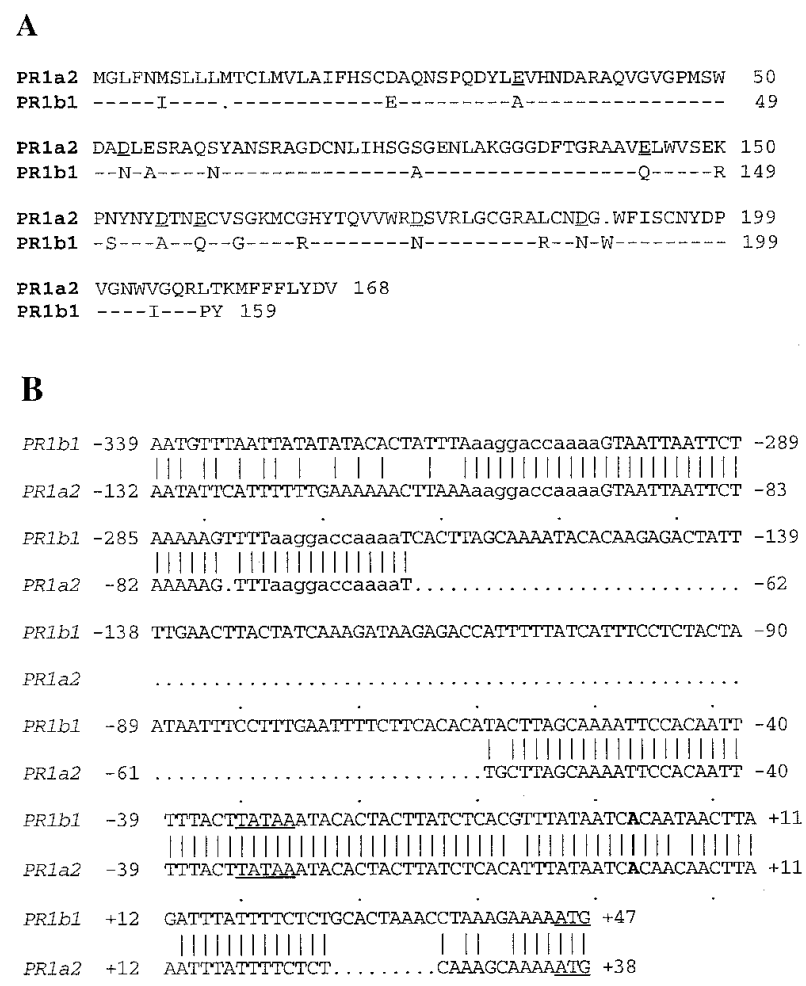

Fig. 2. A, Comparison of the amino acid sequences of the deduced PR1a2 and PR1b1 proteins. B, Comparison of the nucleotide sequences of the 5' proximal promoter regions in the PRIb1 and PRIa2 genes. 
PRlbl to the ATG initiation codon of the GUS coding sequence and the $3^{\prime}$ nopaline synthase (NOS) regulatory sequences (Fig. 3) of the binary vector pBI101 (Jefferson et al. 1987). The chimeric PRla2/GUS gene was constructed similarly by fusion of the region from nucleotide $-1,600$ to nucleotide +47 of PRla2 to the ATG initiation codon of the GUS coding sequence in $\mathrm{pBI} 101$. Site-directed promoter deletions at nucleotide -418 of PRIbl and nucleotide -334 of PRIa2 were also fused to GUS (Fig. 3) and introduced into N. tabacum cv. Xanthi.

To study the spatial distribution of GUS activity driven by these $P R 1$ promoters during different developmental stages of growth, GUS activity was determined in seedlings and in fullgrown plants. GUS activity as revealed by fluorometric determination was five to 30 times higher in stems, roots, and leaves of individual plants harboring the PR1a2/GUS construct than in control (untransformed) plants, but the transgene retained the same spatial and temporal pattern of expression in all the independent transformants, as revealed by histochemical detection of GUS. The resulting pattern of expression observed in different transgenic lines is summarized in Figure 4. PRla2/GUS expression was initially detected in shoot meristem or in meristematic regions of axillary buds soon after true leaves appeared on the plant (Fig. 4C). This meristemspecific expression was maintained in full-grown plants (Fig. 4D). As the seedlings developed and enlarged, the transgene was observed to be expressed gradually along the vascular strands of petioles and leaves (compare Fig. 4A and B). This vascular-specific expression was also observed in fully expanded leaves, where GUS activity was specifically detected in major and minor veins all along the leaf blade, as well as in trichomes (Fig. 4H and I). In petioles the expression was associated with trichomes and subepidermal cortical cells, which became intensively stained for GUS activity (Fig. 4G and H). In the central axis of a mature plant, GUS activity was localized, prominently, in the node regions. Here (Fig. 4E and F), it appeared as if the PRla2/GUS transgene followed a gradient mode of expression along vascular strands emanating from the node. The expression was highest in the central vasculature where the leaf trace connects, as well as in the external (adaxial) cortical cells and trichomes. Along the internodes of the stem of a full-grown plant, PRla2 promoter expression was gradually activated as the stem matured. Here, GUS activity was associated externally with cells of the cortex and internally with pith parenchyma cells in internodes that had initiated secondary growth as well as in ray parenchyma cells of the differentiated xylem tissue (Fig. 4J and K). In the younger internodes, which were closer to the shoot apex and apparently had not yet initiated secondary growth, no GUS activity could be detected, in contrast to the highly localized expression in the shoot meristem (Fig. 4D). In roots, GUS activity was detected in the older parts (e.g., where the main root merges with the stem), while in flowers GUS activity was nearly undetectable, if not absent (data not shown).

This developmental pattern of expression was maintained, albeit with some reduction in the intensity of GUS activity (particularly in trichomes), in transgenic plants harboring the (-334)PRla2/GUS deleted construct (not shown).

In marked contrast, similar analysis of transgenic plants harboring the (-914)PR1bl/GUS construct or the deleted (-418)PR1b1/GUS version revealed no constitutive expression in any of the tissues analyzed above (data not shown) but rather showed a reproducible and predictable induction upon pathogen attack or SA treatments, as expected for a bona fide PR gene (see below).

\section{TMV-induced expression of the chimeric PR1b1/GUS but not the PR1a2/GUS in transgenic tobacco plants}

TMV-mediated induction has been confirmed in transgenic tobacco plants harboring promoter-GUS fusions of endogenous acidic PR-1 genes (Van der Rhee et al. 1990; Oshima et al. 1990). Because of the parallelism in the existence of $P R-1$ genes in tobacco and tomato, we comparatively studied the effect of TMV infection on the expression of PRIb1/GUS and PRla2/GUS in transgenic tobacco plants. A summary of the assay data in some of these transgenic lines is given in Table 1. Transgenic plants containing (-914)PR1b1/GUS showed a 20- to 100-fold induction of GUS activity in leaves at $60 \mathrm{~h}$ after infection with TMV and showing the characteristic HR. No detectable induction was observed in the upper, uninoculated leaves of the same plants 6 to 8 days after inoculation with TMV. Transformants containing (-418)PRIbl/GUS had apparently lost the intense inducibility by TMV infection and only underwent a twofold to 12 -fold induction in inoculated leaves. Negligible GUS activity was found in mock-inoculated plants or control plants lacking the chimeric GUS constructs.
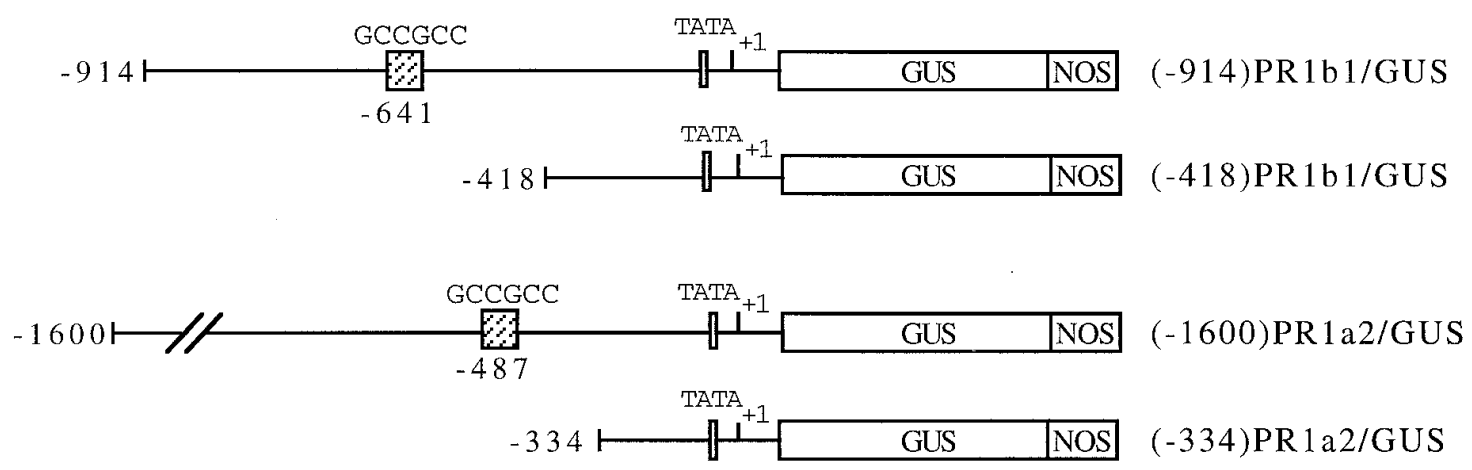

Fig. 3. Chimeric PR1b1/GUS and PRIa2/GUS genes used in this study. The acceptor plasmid for all the promoter fragments tested was pBI101.1. Numbers indicate the distance (in base pairs) from the proximal transcription start site $(+1)$. The relative positions of the putative regulatory element (GCCGCCTC) discussed in the text are shown in shaded boxes. The TATA boxes are indicated by an empty rectangle. 
These GUS activity data allowed us to conclude that some sequences between position -914 and position -418 upstream of the PR1b1 coding region are necessary for maximal induction during the HR induced by TMV.

Similar experiments performed with transgenic tobacco plants harboring either $(-1,600) P R 1 a 2 / G U S$ or $(-334) P R 1 a 2 /$ $G U S$ revealed an opposite pattern of expression for the chimeric gene (Table 1). Upon TMV infection, no induced expression over basal levels of GUS activity driven by the $-1,600$ PRla2 promoter could be found in the TMV-inoculated leaves which were undergoing HR, but instead a slight reduction with respect to mock-inoculated plants was observed in tissues showing necrotic lesions. In the upper, uninoculated leaves, which were to develop the SAR response, no apparent variation in the expression pattern was observed with respect to mock-inoculated plants. Similar results were obtained when transgenic plants containing the deleted (-334)PRla2/GUS gene were inoculated with TMV (Table 1).

This different mode of expression was further confirmed by direct visualization of GUS activity in intact tissues. In all the kanamycin-resistant progenies analyzed that harbored the chimeric (-914)PR1b1/GUS construct, GUS activity was activated during the HR to TMV infection. The gene was expressed at high levels in the tissue immediately surrounding a

Table 1. Local and systemic induction of GUS activity in transgenic tobacco plants harboring promoter-GUS fusions after TMV infection ${ }^{\mathrm{a}}$

\begin{tabular}{|c|c|c|c|}
\hline \multirow[b]{2}{*}{ Construct } & \multirow{2}{*}{$\begin{array}{c}\text { Mock- } \\
\text { inoculated } \\
\text { plants }\end{array}$} & \multicolumn{2}{|c|}{ TMV-infected plants } \\
\hline & & $\begin{array}{c}\text { Inoculated } \\
\text { leaves }\end{array}$ & $\begin{array}{c}\text { Uninoculated } \\
\text { leaves }\end{array}$ \\
\hline (-914)PR1b1/GUS & 200 & 16,400 & 350 \\
\hline$(-418) P R 1 b 1 / G U S$ & 90 & 2,060 & 130 \\
\hline$(-1,600) P R 1 a 2 / G U S$ & 3,000 & 2,600 & 3,200 \\
\hline$(-334) P R 1 a 2 / G U S$ & 2,200 & 1,800 & 2,000 \\
\hline
\end{tabular}

${ }^{a}$ GUS activity was analyzed fluorometrically as described in Materials and Methods; the data are expressed as pmol of 4-methyl umbelliferone/ min per $\mathrm{mg}$ of protein. GUS activity was determined in $F_{1}$ progeny of three independent transformants for each construct at $72 \mathrm{~h}$ after mock inoculation or inoculation with TMV. The data represent the average GUS activity observed in two plants of each transgenic line.
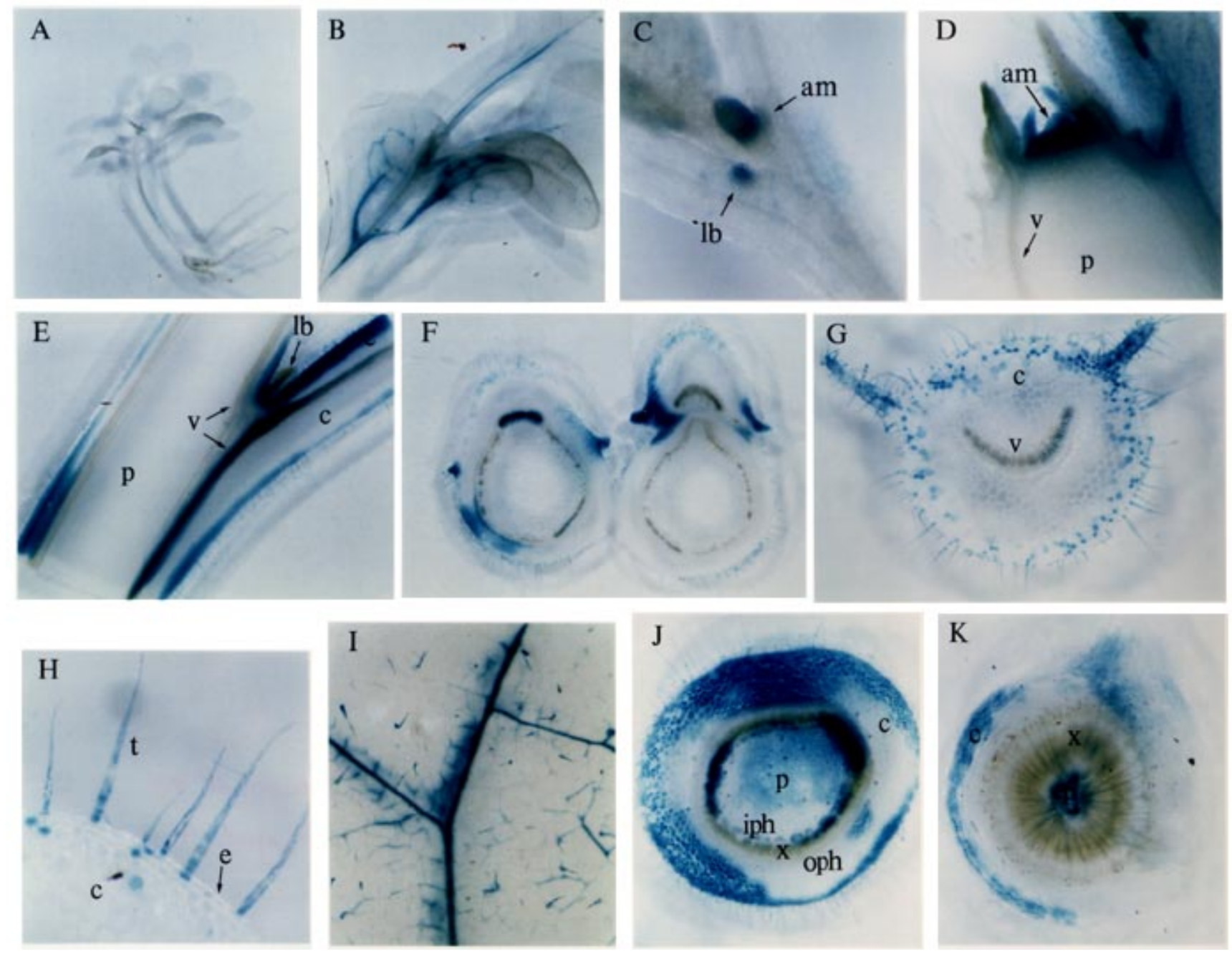

Fig. 4. Localization of GUS activity in transgenic tobacco seedlings transformed with the $(-1,600) P R 1 a 2 / G U S$ construct. A-C, Seedling stage. D, Longitudinal section of shoot apical meristem of a full-grown plant. $\mathbf{E}$, Longitudinal section of a mature node. $\mathbf{F}$, Cross sections of a node like that in $\mathbf{E}$ at two successive stages of leaf trace connection. $\mathbf{G}$ and $\mathbf{H}$, Petiole cross section. I, Magnification of the adaxial leaf surface. $\mathbf{J}$ and $\mathbf{K}$, Internode cross sections at two different stages of stem maturation: intermediate internode $(\mathbf{J})$ and internode at the base of the plant $(\mathbf{K})$. am $=$ Apical meristem; $\mathrm{c}=$ cortex; $\mathrm{e}=$ epidermis; $\mathrm{iph}=$ internal phloem; $\mathrm{lb}=$ lateral $\mathrm{bud} ; \mathrm{oph}=$ outer phloem; $\mathrm{p}=$ pith parenchyma; $\mathrm{t}=$ trichomes; $\mathrm{v}=$ vascular tissue; $\mathrm{x}=\mathrm{xylem}$. 
local lesion, as indicated by distinct blue staining around each lesion at 60 to $72 \mathrm{~h}$ after inoculation (Fig. 5A, left). Later (4 to 5 days after inoculation), when necrotic lesions were fully developed, GUS activity was detected at greater distances from the lesion and in a more diffuse manner (not shown). Similar analysis in transgenic tobacco plants expressing the deleted $(-418) P R 1 b 1 / G U S$ showed that the transgene was still activated following TMV inoculation, but the extent of induction

\section{(-914)PR1b1/GUS}

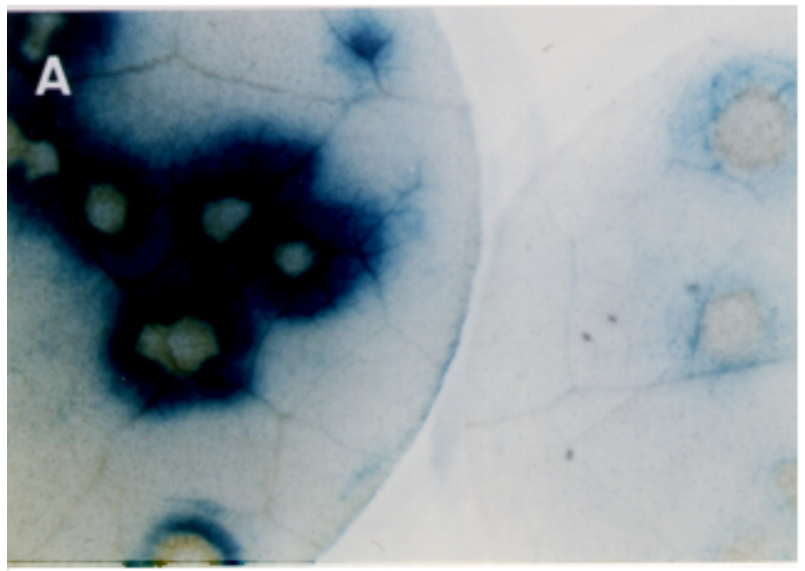

(-914)PR1b1/GUS

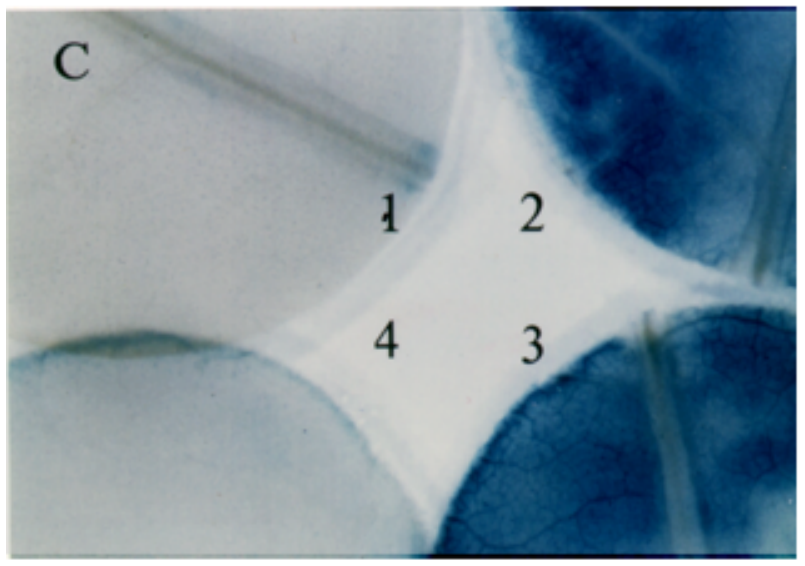

(-418)PR1b1/GUS

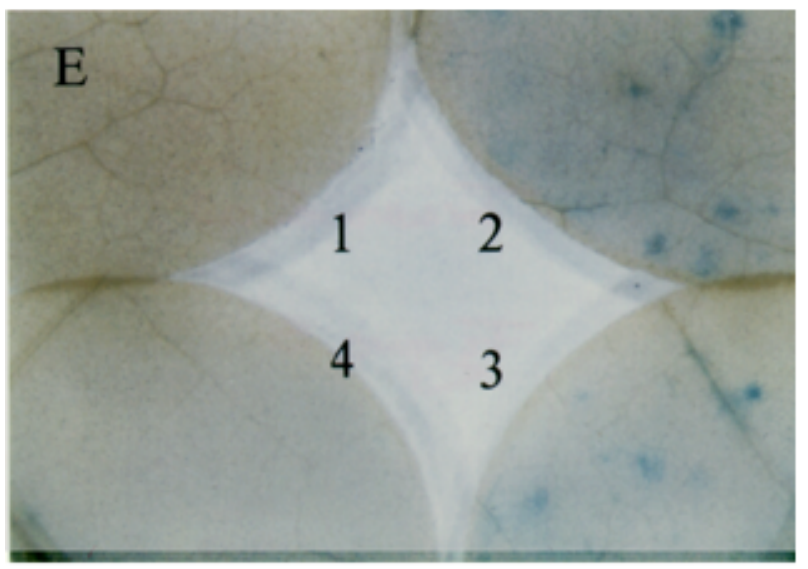

$(-1600) P R 1 a 2 / G U S$

(-334)PR1a2/GUS

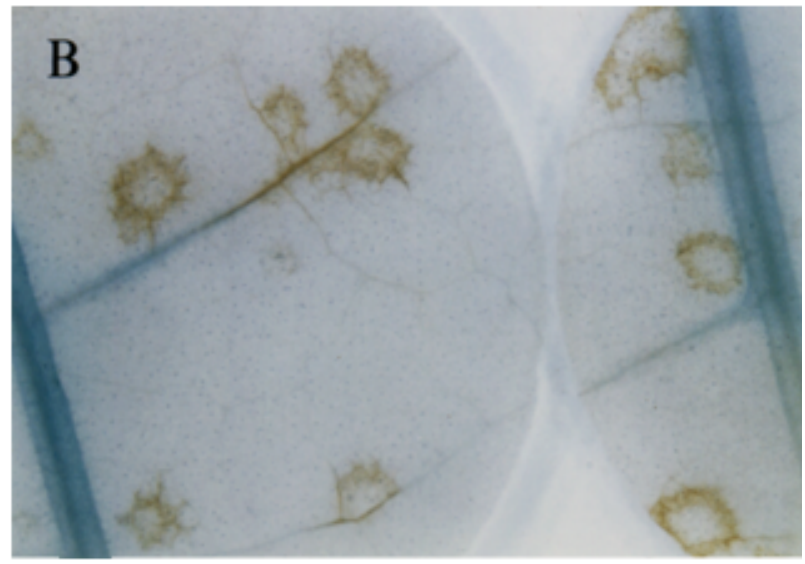

(-1600)PR1a2/GUS

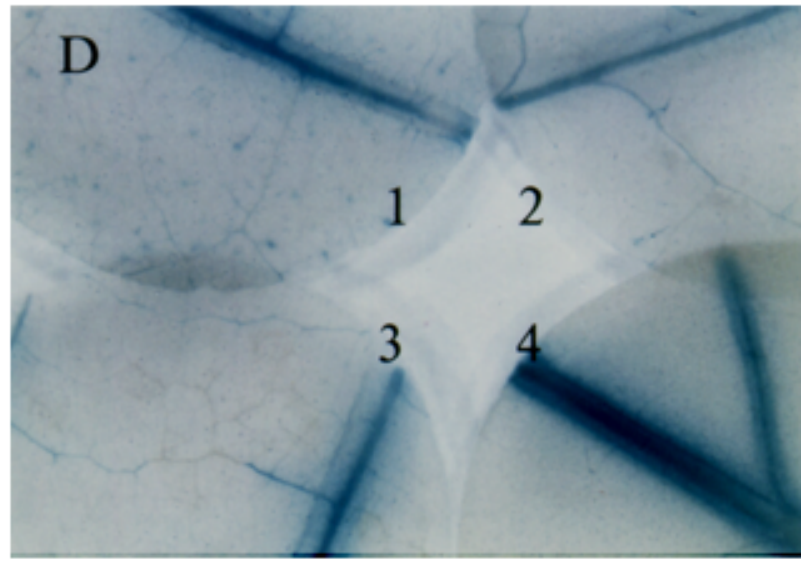

(-334)PR1a2/GUS

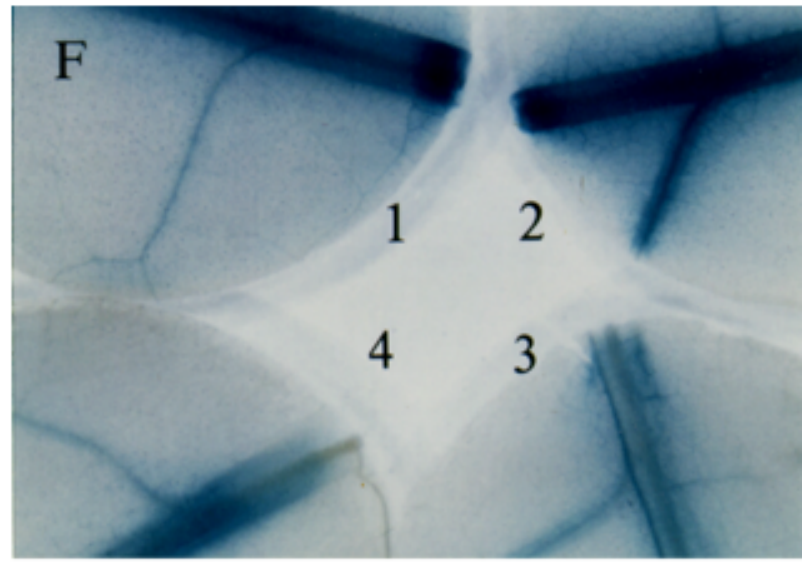

Fig. 5. Localization of TMV-induced and chemically induced expression of the GUS gene in transformed plants. A, GUS expression in leaf tissue 3 days after inoculation with TMV: plants containing (-914)PR1b1/GUS (left) and (-418)PR1b1/GUS. B, GUS expression in leaf tissue 3 days after inoculation with TMV: plants containing $(-1,600) P R 1 a 2 / G U S$ (left) and (334)PRla2/GUS. C-F, Leaf disks from transformants containing (-914)PR1b1/ GUS (C), (-1,600)PR1a2/GUS (D), (-418)PR1b1/GUS (E), and (-334)PRla2/GUS (F) $48 \mathrm{~h}$ after flotation in buffer (disk 1), in buffer plus $0.5 \mathrm{mM}$ salicylic acid (disk 2), in buffer plus $0.5 \mathrm{mM}$ ethephon (disk 3), or in buffer plus $0.5 \mathrm{mM} \mathrm{H}_{3} \mathrm{PO}_{3}$ (disk 4). 
was notably reduced (Fig. 5A, right). GUS activity was not found in the upper, uninoculated leaves of plants with either of these two PR1b1 chimeric genes at least 6 to 8 days after inoculation (data not shown). TMV infection of transformants containing the chimeric $(-1,600) P R 1 a 2 / G U S$ or $(-334) P R 1 a 2 /$ GUS revealed no superimposed induction of GUS activity over the already established expression pattern. For these two constructs no activation was observed in the tissue immediately surrounding a local lesion at any time during the infection process (Fig. 5B). Thus, during infection and around the infection site the basic PRIbl gene is strongly expressed, while the acidic PRla2 gene is unaltered or partially downregulated.

\section{The PR1b1 but not the PR1a2 promoter activity is enhanced by $\mathrm{SA}$ and ethylene precursors.}

$\mathrm{SA}$ is one of the possible endogenous signal molecules mediating the SAR response in tobacco and has been shown to be increased in tissues undergoing TMV-induced HR. Also, when applied exogenously, SA induces the expression of acidic PR genes in tobacco (Ohshima et al. 1990; Van der Rhee et al. 1990; Uknes et al. 1993; Yalpani et al. 1991; Ward et al. 1991).

Initial experiments using a leaf disk assay (Van der Rhee et al. 1990) were performed to determine the effect, if any, of SA and the optimal concentration of SA for achieving maximal induction of the chimeric genes. Leaf disks were treated with increasing concentrations of SA for $48 \mathrm{~h}$ at room temperature, harvested, and assayed for GUS activity. GUS activity increased linearly with increasing SA concentrations up to 4 $\mathrm{mM}$ for the full PRIbl promoter (data not shown). At higher concentrations of SA, the measured GUS activity declined, and it was almost completely inhibited by $10 \mathrm{mM}$ SA. Treatment of disks with SA at concentrations below $0.02 \mathrm{mM}$ produced no detectable induction of GUS activity. The expression of the deleted (-418)PRIbl/GUS construct was notably reduced after SA treatment, compared to that of the full promoter (Table 2). As was the case with TMV infection, these results suggest that regulatory regions governing the SAmediated induction lie between position $-1,000$ and position -418 . Conversely, the expression of full or deleted promoterGUS fusions of the acidic PRla2 gene was not altered, compared to that of control disks treated with buffer (Table 2).

Histochemical staining of leaf tissues that had been treated with $0.5 \mathrm{mM}$ SA confirmed these differences. The basic (-914)PR1b1/GUS transgene was mainly expressed in leaf parenchyma tissues but only slightly in leaf veins, which showed very weak blue coloration (compare disks 1 and 2 in Fig. 5C). The deleted (-418)PR1b1/GUS gene showed a drastic reduc- tion in the induction level upon SA treatment (disks 1 and 2 in Fig. 5E). As expected, no effect of SA was observed in the full or deleted PRla2/GUS transgenes, in which expression was restricted to vascular bundles of the leaf (disks 1 and 2 in Fig. $5 \mathrm{D}$ and $\mathrm{F})$.

Northern blot analyses of tobacco have revealed that genes encoding PR proteins with a basic pI are expressed upon treatment with the ethylene-releasing compound ethephon (2-chloroethylphosphonic acid) (Brederode et al. 1991; Linthorst et al. 1993). Moreover, Eyal et al. (1993) have described the characterization of a basic-type $P R-1$ tobacco gene ( $P R B$ $1 b$ ) belonging to an ethylene-responsive gene subfamily whose regulation is distinct from that of the acidic-type $P R-1$ genes. The ethylene-induced expression of $P R B-1 b / G U S$ constructs, when assayed in transgenic tobacco plants, is mediated by the presence of an 8-bp cis element (GCCGCCTC) in the minimal promoter of this gene. This element is present in promoter regions of other genes encoding different basic PR proteins from tobacco (Eyal et al. 1993 and references therein) and is also found in the promoters of the two tomato $P R-1$ genes presently described. This indicates that ethylene may be a signal for the specific expression of these two $P R-1$ genes.

To test this possibility, we treated leaf tissue of transgenic plants with the ethylene precursor 1-aminocyclopropane-1carboxylate (ACC) or with ethephon. Ethephon $(0.5 \mathrm{mM})$ or ACC $(0.1 \mathrm{mM})$ activated the expression of the PRIbl gene (Table 2). As was the case for SA-mediated induction, ethephon induced the expression of the PRIb1/GUS transgene which was localized in the parenchymatic tissue and not in the veins (disk 3 in Fig. 5C). Similar observations were made after ACC treatment (not shown). Ethylene precursors had no effect in the (-418)GUS construct, which lacks the GCCGCCTC element (Table 2; disk 3 in Fig. 5E). Control experiments of leaf disks treated with buffer alone, $0.5 \mathrm{mM}$ phosphonic acid $\left(\mathrm{H}_{3} \mathrm{PO}_{3}\right)$, or hydrochloric acid $(\mathrm{HCl})$, which are breakdown products generated during the conversion of 2chloroethylphosphonic acid to ethylene (Yang 1969), resulted in no induction of the gene (Table 2; disk 4 in Fig. 5C and E). Conversely, expression of the acidic PRla2/GUS constructs (Table 2) was unaffected by ACC or ethephon, and the expression remained restricted to previously established tissues (e.g., leaf veins) (Fig. 5D and F), suggesting that the 8-bp cis element is nonfunctional in this promoter context.

All these results suggest that both ethylene and SA, either produced by TMV infection or applied to tissues, are potential pathogenic signals which act positively on the expression of the basic PRIbl gene but have no effect on the expression of the acidic PRla2 counterpart.

Table 2. GUS activity induced by different chemicals in transgenic tobacco plants harboring promoter-GUS constructs

\begin{tabular}{|c|c|c|c|c|c|c|}
\hline \multirow[b]{2}{*}{ Construct } & \multicolumn{6}{|c|}{ Treatment $^{\mathrm{a}}$} \\
\hline & Buffer & SA & ACC & Ethephon & $\mathrm{H}_{3} \mathrm{PO}_{3}$ & HCl \\
\hline (-914)PR1b1/GUS & 400 & 28,400 & 18,000 & 26,000 & 1,060 & 1,200 \\
\hline$(-418) P R 1 b 1 / G U S$ & 112 & 3,360 & 940 & 1,050 & 330 & NT \\
\hline$(-1,600)$ PR1a2/GUS & 3,700 & 3,500 & 3,500 & 4,080 & 2,900 & 3,200 \\
\hline$(-334) P R 1 a 2 / G U S$ & 3,010 & 3,060 & 3,200 & 3,331 & NT & NT \\
\hline
\end{tabular}

${ }^{a}$ Leaf disks from transgenic plants were assayed for GUS activity after flotation for $48 \mathrm{~h}$ on buffer solution, buffer solution containing $0.5 \mathrm{mM}$ salicylate (SA), $0.1 \mathrm{mM}$ 1-aminocyclopropane-1-carboxylate (ACC), $0.5 \mathrm{mM}$ ethephon, $1 \mathrm{mM}$ phosphonic acid $\left(\mathrm{H}_{3} \mathrm{PO}_{3}\right), 1 \mathrm{mM}$ hydrochloric acid (HCl). For each construct, the average GUS activity in two $F_{1}$ plants derived from two independent primary transformants is given. NT $=$ not tested. 


\section{DISCUSSION}

Here we describe the characterization of two closely related genes from tomato plants encoding basic (PR1b1) and acidic (PR1a2) members of the pathogenesis-related PR-1 family. Comparison of the PRIb1 and PRIa2 nucleotide and amino acid sequences reveals remarkable homology all along the coding regions (Figs. 1 and 2) except in the C-terminal portion, in which the PR1a2 isoform contains an extra tail of nine amino acids. This short C-terminal motif may determine a cellular localization of PR1a2 (presumably extracellular) different from that of PR1b1 (presumably vacuolar), as has been suggested for other PR isoforms (Neuhaus et al. 1991). This high homology extends even outside the ORF, either toward the $3^{\prime}$ end or the $5^{\prime}$ promoter region (Figs. 1 and 2A), and thus it seems likely that the two genes arose through a recent gene duplication event.

In spite of this strong conservation, the two genes have highly divergent expression patterns in transgenic tobacco plants using chimeric genes constructed by fusion of their promoter regions to the GUS reporter gene. Transformants containing the GUS gene under the control of the full and a deleted $5^{\prime}$ promoter region of the acidic PRla 2 gene showed no inducibility by TMV infection or pathogenic signals such as SA or ethylene but rather demonstrated a reproducible transcriptional activation which appears to be governed by developmental cues (Fig. 4). On the other hand, parallel analysis of transgenic plants containing the $P R I b 1$ promoter-GUS fusion did not reveal any detectable constitutive expression. This indicates that, unlike the acidic $P R-1$ gene, the one encoding the basic isoform is not under developmental regulation.

The confined transcriptional activation of the PRla2 gene in the above-mentioned tissues constitutes an unexpected example of a precise mechanism of constitutive expression of a $P R$ gene. How such a cell-type-specific expression pattern has evolved from common ancestral and pathogen-inducible genes, or vice versa, and how its expression is interpreted by the healthy plants remains unknown. Other defense-related genes also show constitutive expression and are under developmental regulation (Lotan et al 1989; Zhu et al. 1993; Constabel et al. 1995; Liang et al. 1989). However, these differ from PRla2 in being induced by pathogenic signals in previously silent tissues.

Although we cannot disregard the possibility that the encoded acidic PR1a2 protein may have a nondefensive metabolic function, we may speculate that the expression of this gene may be related to its participation in a certain type of immunity and that this mode of gene regulation may be the basis of why plants show natural resistance to certain types of pathogens. This argument may gain acceptance if we consider that transgenic plants constitutively expressing the homolog PR-1a isoform gene from tobacco under the control of the $35 \mathrm{~S}$ promoter have increased tolerance to the fungal pathogens Phytophthora parasitica and Peronospora tabacina (Alexander et al. 1993), implying that $P R-1$ genes play a role in disease resistance. Thus, it appears as if plants may have evolved a complementing set of both constitutive and inducible $P R-1$ genes, which may be the basis for an explanation of the broadspectrum immunity of plants to most pathogens.

At variance with $P R I a 2$, the $P R I b 1$ gene shows a reproducible pathogen-mediated inducibility, as observed after TMV inoculation (Fig. 5). This induction occurred in the tissues immediately surrounding necrotic lesions and concurs with the reported accumulation of endogenous PR-1 proteins from tobacco (Antoniw and White 1986). Conversely, while endogenous tobacco genes (referred to as SAR genes) are concomitantly induced in upper, uninoculated leaves upon TMV infection (Brederode et al. 1991; Ward et al. 1991; Lawton et al. 1993), the PRIbl gene under consideration is not.

Regulatory elements controlling pathogen induction of genes encoding PR proteins have been characterized in a number of cases; however, they are widely different, making it difficult to define a minimal promoter necessary for pathogen induction of different $P R$ genes. A well-conserved DNA motif has been found to be present in a number of genes encoding basic isoforms of PR proteins (Meller et al. 1993; Alonso et al. 1995; Eyal et al. 1993 and references therein). In these genes, the GCCGCCTC sequence motif is present and appears to be necessary for local induction of gene expression in an ethylenedependent manner. This same motif is present in the tomato PRIbl and is thus a potential cis-acting element for the regulation of expression of this gene member. In fact, transgenic plants harboring a $5^{\prime}$ deletion in the PRIbl promoter (to -418), which eliminates this 8-bp motif, present a drastic reduction of expression upon TMV infection, suggesting that this conserved DNA motif may also be necessary for full expression of PRIbl, as has been deduced for other PR genes encoding proteins with basic pI. Since the GCCGCCTC motif has been shown to mediate ethylene activation, it is tempting to speculate that the induction of $P R I b 1$ is, at least partly, controlled by the level of endogenous ethylene produced by TMV infection. This gains support if we consider that ethylene has long been known to be produced when cells undergo necrosis resulting from pathogen infection (Ross and Williamson 1951; De Laat and Van Loon 1982, 1983) and is consistent with the fact that genes encoding ethylene-biosynthetic enzymes are induced locally as a result of TMV infection (Knoester et al. 1995). Similarly, the absence of TMV-induced expression of the genes for ethylene biosynthesis in the uninoculated, systemic leaves (Knoester et al. 1995) corresponds to the absence of TMV-induced gene expression for PRIb1/GUS in these leaves (Table 1). Furthermore, the PRIbl gene is strongly induced by low concentrations of the ethylene precursor ACC or by the ethylene-releasing ethephon (Fig. 5), and mRNA accumulation for this gene in tomato plants is suppressed by inhibitors of ethylene action (Tornero et al. 1994). All this points toward a role for ethylene in the local expression of PR genes with a basic pI, or at least some members of this subclass, during the HR. However, this PRlbl gene is also inducible by $\mathrm{SA}$, and this finding indirectly supports the notion that different signaling processes may operate to set in motion the expression of basic and acidic PR genes.

A variety of mutants displaying increased resistance to pathogen attack have been described (for a recent review, see Hunt and Ryals [1996]). In these mutants, SAR responses are activated in the absence of pathogen infection and always contain elevated levels of SA and increased expression of SAR marker genes (Greenberg and Ausubel 1993; Dietrich et al. 1994; Bowling et al. 1994). Additionally, the signal transduction mediating SAR has been demonstrated to be ethyleneindependent in Arabidopsis (Lawton et al. 1994). Furthermore, SA applied to plant tissue has been shown not to be converted 
to ethylene (Van Loon and Antoniw 1982), while local application of the ethylene precursor ACC or ethephon to plant tissues (J. Fallos et al., unpublished results) provokes rapid and long-lasting increases in SA. All these observations support the hypothesis that there are at least two classes of signal transduction pathways activated during incompatible plantpathogen interactions and that differentially set in motion expression of $P R$ genes and presumably other defense responses. One is activated locally and involves ethylene as a transient pathogenic signal that coexists with or can signal the enhancing of SA. This pathway appears to be able to activate local defenses (e.g., basic isoforms of PR proteins) but is independent of SAR or not associated with it. The other signaling process, which appears to be independent of ethylene but mediated by SA, is associated with SAR in a long-lasting way and is accompanied by the expression of acidic PR members, but not basic ones, in distant tissues.

In support of this duality are the recent results of Beffa et al. (1996), who demonstrated two different classes of signaling pathways, mediated by G-proteins, in transgenic plants expressing the cholera toxin (CTX). One class, which is insensitive to CTX, is associated with HR and is required for induction of class I PR-2 and PR-3 proteins by ethylene. The second class, which is activated by CTX, is required for SAR-associated induction of acidic PR-1 and class II PR-2 and PR-3 proteins. Furthermore, in an attempt to genetically dissect the signal transduction regulating defense responses in Arabidopsis, Glazebrook et al. (1996) have shown that eds5, which is an enhanced disease susceptibility mutant and allelic to mutant nprl, a nonexpresser of PR genes (Cao et al. 1994), does not induce $P R-1$ in response to SA but shows induced expression of PR-1 upon infection with Pseudomonas syringae (Psm ES4326). This observation can be explained as if induction of $P R-1$ expression in response to bacterial infection results from the combined effect of two signaling pathways, one that is mediated by SA through NPRI and one that is NPRl-independent and may involve ethylene as a local inducer. The existence of more than one signaling pathway is further supported by the observation of Green and Fluhr (1995) that the UV-B induction of an SAR marker gene, $P R-1$, is independent of SA action but mediated by active oxygen species which could be originated through the activation of a parallel signaling process.

How these different signaling processes are interlinked and how they operate to set in motion different batteries of plant defenses, either locally or in distant tissues, in such a precise and coordinated fashion remains enigmatic. Comparative studies of different plant-pathogen interactions using either constitutive, HR-, or SAR-specific $P R$ promoters as molecular tools will help address these questions in future experiments.

\section{MATERIALS AND METHODS}

\section{Plant material and growth conditions.}

All plants were grown at $22^{\circ} \mathrm{C}$ in growth chambers programmed for a cycle of $14 \mathrm{~h}$ of light and $10 \mathrm{~h}$ of darkness.

\section{Library screening and DNA sequence analysis.}

Library screening using radiolabeled cDNA was performed as previously described (Tornero et al. 1994). A tomato genomic DNA library constructed in $\lambda$-EMBL3 (Clontech) was screened with a radiolabeled pTE28.1 cDNA probe (Tornero et al. 1993), and the positive clones were isolated and purified by standard techniques (Maniatis et al. 1982). DNA sequencing and computer-assisted comparison of DNA sequences were performed as described before (Tornero et al. 1994).

\section{Promoter-GUS fusions, plant transformation, and analysis of transgenic plants.}

Oligonucleotides o17.2 (5'-GGGATCCTTTAGGTTTAGTGCAG-3') and oR3-1 (5'-GGGATCCGCTTTGAGAGAAAAT-3') served as primers for the incorporation of synthetic BamHI restriction sites in the PRIbl and PRIa2 upstream sequences, respectively, by site-directed mutagenesis (Kunkel et al. 1987). The synthetic BamHI site was introduced into the promoters upstream regions at positions -1 relative to the translation initiation site. A blunt-ended BamHI fragment containing PRIbl promoter sequences -914 to +56 relative to the transcription start site was cloned upstream of the $\beta$-glucuronidase gene in pBI101.1 (Jefferson et al. 1987). An XbaIBam HI fragment containing PR1a2 promoter sequences $-1,600$ to +47 was similarly cloned in pBI101.1. Promoter deletions were carried out by using internal restriction sites (HindIII). The resulting fusions were verified by nucleotide sequence analysis using primers specific for the promoter region of each gene. The resulting plasmids were then mobilized into Agrobacterium tumefaciens LBA 4044 as described by Bevan (1984). Leaf disks of N. tabacum cv. Xanthi-NC were transformed as described by Horsch et al. (1984). Primary transformants were allowed to self-fertilize, and $F_{1}$ seeds were collected and germinated on MS agar medium containing kanamycin for selection. Transgenic seedlings were then transferred to soil. Transformants were assayed for GUS activity by a fluorometric assay or by an in situ assay using the colorigenic substrate X-Gluc (Jefferson 1987). For each construct, expression was determined in at least five independent transgenic lines.

\section{Induction of the PRIa2/GUS and PR1b1/GUS genes.}

Seven- to 8-week-old plants were used for protein extraction and GUS assays following treatment with chemicals or inoculation with TMV. For induction with SA, ethephon, acid derivatives, or ACC, $1.5-\mathrm{cm}$ disks were punched from leaves of transgenic plants and floated in a petri dish on $30 \mathrm{mM}$ HEPES buffer ( $N$-2-hydroxyethylpiperazine- $N$-2-ethanesulfonic acid, $\mathrm{pH}$ 6.9) containing these chemicals at the indicated concentrations for $48 \mathrm{~h}$ at $22^{\circ} \mathrm{C}$ under a cycle of $14 \mathrm{~h}$ of light and $8 \mathrm{~h}$ of darkness. After incubation, leaf disks were directly analyzed for GUS expression or were frozen and stored at $-70^{\circ} \mathrm{C}$. For inoculation with TMV, leaves of plants were dusted with Carborundum and rubbed with a suspension of TMV strain U1 $(1 \mu \mathrm{g} / \mathrm{ml})$ (provided by I. García, CIB, Spain) in $50 \mathrm{mM}$ phosphate buffer, $\mathrm{pH}$ 7.2. Leaf disks were taken from inoculated leaves at $0,1,2,3$, and 4 days after inoculation and from upper, uninoculated leaves at 4, 6, and 8 days after inoculation.

\section{ACKNOWLEDGMENT}

We thank Jean-Pierre Métraux for critical reading of the manuscript. We acknowledge the financial support of the Spanish Ministry of Science and Education (Grant DGICYT Project No. PB93-0383). 
J.G. and P.T. thank the Conselleria de Educación de la Comunidad Valenciana and the Ministry of Science and Education, respectively, for fellowships.

\section{LITERATURE CITED}

Alexander, D., Goodman, R. M., Gut-Rella, M., Glascock, C., Weymann, K., Friedrich, L., Maddox, D., Ahl-Goy, P., Luntz, T., Ward, E., and Ryals, J. 1993. Increased resistance to two oomycete pathogens in transgenic tobacco expressing pathogenesis-related protein 1a. Proc. Natl. Acad. Sci. USA 90:7327-7331.

Alonso, E., de Carvalho Niebel, E., Obregón, P., Gheysen, G., Inzé, D., Van Montagu, M., and Castresana, C. 1995. Differential in vitro DNA binding activity to a promoter element of the gn1-1,3-glucanase gene in hypersensitively reacting tobacco plants. Plant J. 7:309-320.

Antoniw, J. F., and White, R. F. 1986. Changes with time in the distribution of virus and PR proteins around single local lesions of TMV infected tobacco. Plant Mol. Biol. 6:145-149.

Beffa, R., Szell, M., Meuwly, P., Pay, A., Vögeli-Lange, R., Métraux, J.-P., Neuhaus, G., Meins, F., Jr., and Nagy, F. 1996. Cholera toxin elevates pathogen resistance and induces pathogenesis-related gene expression in tobacco. EMBO J. 23:5753-5761.

Bevan, M. 1984. Binary Agrobacterium vectors for plant transformation. Nucleic Acids Res. 12:8711-8721.

Bowling, S. A., Guo, A., Cao, T., Gordon, A. S., Klessig, D. F., and Dong, X. 1994. A mutation in Arabidopsis that leads to constitutive expression of systemic acquired resistance. Plant Cell 6:1845-1857.

Brederode, F. T., Linthorst, H. J. M., and Bol, J. F. 1991. Differential induction of acquired resistance and PR gene expression in tobacco by virus infection, ethephon treatment, UV light and wounding. Plant Mol. Biol. 17:1117-1125.

Broglie, K., Chet, I., Holliday, M., Cressman, R., Riddle, P., Knowlton, S., Mauvais, C. J., and Broglie, R. 1991. Transgenic plants with enhanced resistance to the fungal pathogen Rhizoctonia solani. Science 254:1194-1197.

Cao, H., Bowling, S. A., Gordon, A. S., and Dong, X. 1994. Characterization of an Arabidopsis mutant that is nonresponsive to inducers of systemic acquired resistance. Plant Cell 6:1583-1592.

Constabel, C. P., and Brisson, N. 1995. Stigma- and vascular-specific expression of the PR-10a gene from potato: A novel pattern of expression of a pathogenesis-related gene. Mol. Plant-Microbe Interact. 8: 104-113.

Cutt, J. R., and Klessig, D. F. 1992. Pathogenesis-related proteins. Pages 209-243 in: Genes Involved in Plant Defense. T. Boller and F. Meins, Jr., eds. Springer, Vienna.

De Laat, A. M. M., and Van Loon, L. C. 1982. Regulation of ethylene biosynthesis in virus-infected tobacco leaves. II. Time course of levels of intermediates and in vivo conversion rates. Plant Physiol. 69:240-245.

De Laat, A. M. M., and Van Loon, L. C. 1983. The relationship between stimulated ethylene production and symptom expression in virusinfected tobacco leaves. Physiol. Plant Pathol. 22:261-273.

Dietrich, R. A., Delaney, T. P., Uknes, S. J., Ward, E. R., Ryals, J. A., and Dangl, J. L. 1994. Arabidopsis mutants simulating disease response. Cell 77:565-578.

Eyal, Y., Meller, Y., Lev-Yadun, S., and Fluhr, R. 1993. A basic-type PR-1 promoter directs ethylene responsiveness, vascular and abscission-specific expression. Plant J. 4:225-234.

Glazebrook, J., Roger, E., and Ausubel, F. M. 1996. Isolation of Arabidopsis mutants with enhanced disease susceptibility by direct screening. Genetics 143:973-982.

Green, R., and Fluhr, R. 1995. UV-B-induced PR1 accumulation is mediated by active oxigen species. Plant Cell 7:203-212

Greenberg, J. T., and Ausubel, F. M. 1993 Arabidopsis mutants compromised for the control of cellular damage during pathogenesis and ageing. Plant J. 4:327-341.

Horsch, R. B., Fraley, R. T., Rogers, S. G., Sanders, P. R., Lloyd, A., and Hoffmann, N. 1984. Inheritance of functional foreing genes in plants. Science 223:496-498.

Hunt, M. D., and Ryals, J. A. 1996. Systemic acquired resistance signal transduction. Crit. Rev. Plant Sci. 15:583-606.

Jefferson, R. A. 1987. Assaying chimeric genes in plants: The GUS gene fusion system. Plant Mol. Biol. Rep. 5:387-405.

Jefferson, R. A., Kavanagh, T. A., and Bevan, M. W. 1987. GUS fusions:
b-Glucuronidase as a sensitive and versatile gene fusion marker in higher plants. EMBO J. 6:3901-3907.

Knoester, M., Bol, J. F., van Loon, L. C., and Linthorst, H. J. M. 1995. Virus-induced gene expression for enzymes of ethylene biosynthesis in hypersensitively reacting tobacco. Mol. Plant-Microbe Interact. 8: 177-180.

Kunkel, T. A., Roberts, J. D., and Zakour, R. A. 1987. Rapid and efficient site specific mutagenesis without phenotypic selection. Methods Enzymol. 154:367-381.

Lawton, K., Uknes, S., Friedrich, L., Gaffney, T., Alexander, D., Goodman, R., Metraux, J.-P., Kessmann, H., Ahl Goy, P., Gut Rella, M., Ward, E., and Ryals, J. 1993. The molecular biology of systemic acquired resistance. Pages 410-420 in: Mechanisms of Defense Responses in Plants. B. Fritig and M. Legrand, eds. Kluwer Academic, Dordrecht.

Lawton, K. A., Potter, S. L., Ukness, S., and Ryals, J. 1994. Acquired resistance signal transduction in Arabidopsis is ethylene independent. Plant Cell 6:581-588.

Liang, X., Dron, M., Schmid, J., Dixon, R. A., and Lamb, C. J. 1989. Developmental and environmental regulation of a phenylalanine ammonia-lyase- $\beta$-glucuronidase gene fusion in transgenic tobacco plants. Proc. Natl. Acad. Sci. USA 86:9284-9288.

Linthorst, H. J. M., Brederode, F. T., Van der Does, C., and Bol, J. F. 1993. Tobacco proteinase inhibitors-I genes are locally, but not systemically induced by stress. Plant Mol. Biol. 21:985-992.

Lotan, T., Ori, N., and Fluhr, R. 1989. Pathogenesis-related proteins are developmentally regulated in tobacco flowers. Plant Cell 1:881-887.

Maniatis, T., Fritsch, E. F., and Sambrook, J. 1982. Molecular Cloning: A Laboratory Manual. Cold Spring Harbor Laboratory, Cold Spring Harbor, NY.

Matthews, R. E. F. 1991. Plant Virology. 3d ed. Academic Press, San Diego, CA.

Mauch, F., Mauch-Mani, B., and Boller, Y. 1988. Antifungal hydrolases in pea tissue. II. Inhibition of fungal growth by combinations of chitinase and $\beta$-1,3-glucanase. Plant Physiol. 88:936-942.

Meller, Y., Sessa, G., Eyal, Y., and Fluhr, R. 1993. DNA-protein interactions on a cis-DNA element essential for ethylene regulation. Plant Mol. Biol. 23:453-463.

Metzler, M. C., Cutt, J. R., and Klessig, D. F. 1991. Isolation and characterization of a gene encoding a PR-1 like protein from Arabidopsis thaliana. Plant Physiol. 96:346-348.

Neuhaus, J. M., Sticher, L., Meins, F., and Boller, T. 1991. A short $\mathrm{C}$-terminal sequence is necessary and sufficient for the targeting of chitinases to the plant vacuole. Proc. Natl. Acad. Sci. USA 88:1036210366.

Ohshima, M., Itoh, H., Matsuoka, M., Murakami, T., and Ohashi, Y. 1990. Analysis of stress-induced or salicylic acid-induced expression of the pathogenesis-related 1a protein gene in transgenic tobacco. Plant Cell 2:95-106.

Ross, A. F. 1961. Systemic acquired resistance induced by localized virus infections in plants. Virology 14:340-358.

Ross, A. F., and Williamson, C. E. 1951. Physiologically active emanations from virus-infected plants. Phytopathology 41:431-438.

Tornero, P., Conejero, V., and Vera, P. 1994. A gene encoding a novel isoform of the PR-1 protein family from tomato is induced upon viroid infection. Mol. Gen. Genet. 243:47-53.

Tornero, P., Rodrigo, I., Conejero, V., and Vera, P. 1993. Nucleotide sequence of a cDNA encoding a "pathogenesis-related" (PR) protein P1-p14 from tomato. Plant Physiol. 325:102.

Uknes, S., Dincher, S., Friedrich, L., Negrotto, D., Williams, S., Thompson-Taylor, H., Potter, S., Ward, E., and Ryals, J. 1993. Regulation of pathogenesis-related protein-1a gene expression in tobacco. Plant Cell 5:159-169.

Uknes, S., Mauch-Mani, B., Moyer, M., Williams, S., Dincher, S., Chandler, D., Potter, S., Slusarenko, A., Ward, E., and Ryals, J. 1992. Acquired resistance in Arabidopsis. Plant Cell 4:645-656.

Van der Rhee, M. D., Van Kan, J. A. L., Gonzalez-Jaen, M. T., and Bol, J. 1990. Analysis of regulatory elements involved in the induction of two tobacco genes by salicylate treatment and virus infection. Plant Cell 2:357-366.

Van Kan, J. A. L., Joosten, M. H. A. J., Wagemakers, C. A. M., Van den Berg-Velthuis, G. C. M., and De Witt, P. J. G. M. 1992. Differential accumulation of mRNAs encoding extracellular and intracellular PR proteins in tomato induced by virulent and avirulent races of Clado- 
sporium fulvum. Plant Mol. Biol. 20:513-527.

Van Loon, L. C., and Antoniw, J. F. 1982. Comparison of the effect of salicylic acid and ethephon with virus-induced hypersensitivity and acquired resistance in tobacco. Neth. J. Plant Pathol. 88:237-256.

Ward, E. R., Uknes, S. J., Williams, S. C., Dincher, S. S., Wiederhold, D. L., Alexander, D. C., Ahl-Goy, P., Métraux, J. P., and Ryals, J. A. 1991. Coordinate gene activation in response to agents that induce systemic acquired resistance. Plant Cell 3:1085-1094.

Yalpani, N., Silverman, P., Wilson, T. M. A., Kleier, D. A., and Raskin, I. 1991. Salycilic acid is a systemic signal and an inducer of pathogene- sis-related proteins in virus-infected tobacco. Plant Cell 3:809-818.

Yang, S. F. 1969. Ethylene evolution from 2-chloroethylphosphonic acid. Plant Physiol. 44:203-1204.

Zhu, Q., Doerner, P. W., and Lamb, C. J. 1993. Stress induction and developmental regulation of a rice chitinase promoter in transgenic tobacco. Plant J. 2:203-212.

Zhu, Q. E., Maher, S., Masoud, R., Dixon, R., and Lamb, C. J. 1994. Enhanced protection against fungal attack by constitutive coexpression of chitinase and glucanase genes in transgenic tobacco. Biotechnology 12:807-812. 